\title{
Temperature-Sensitive Properties of Gold and Gold Alloy Electrodeposits
}

\author{
Ch. J. Raub, H. R. Khan and J. Lendvay \\ Forschungsinstitut für Edelmetalle und Metallchemie, Schwäbisch Gmünd, West Germany \\ The electronics industry demands highly reliable components while \\ economic considerations require the use of mass production techniques \\ for their manufacture. These two, perhaps divergent, factors are \\ most likely to be satisfied when the properties of the many materials \\ used are fully established and generally known. This paper reviews \\ the effects of heat treatment on the surface features and mechanical \\ properties of fine gold, gold-cobalt and gold-nickel electrodeposits \\ and provides some interesting information on the magnetic suscep- \\ tibility and electrical conductivity of gold-cobalt deposits.
}

The use of electrodeposited gold and gold alloys in the electronics industry for the mass production of parts which are required to be highly reliable has resulted in an increasing interest in the properties of such deposits. A knowledge of these properties enables manufacturers to establish specifications to which parts can be fabricated, thus minimising defects during assembly and failures during use. During production or in service the deposits have to withstand various influences, such as bending during the forming of contacts, heat treatment during soldering or in service, abrasion under various conditions, or chemical attack by reactive substances present in the air or by the acids used in the production of semiconductors.

One of the numerous factors that affects every electrolytically deposited gold layer is temperature, which not only influences the properties of the deposit but can also change the behaviour of the whole coated material. Heat treatment, by assisting diffusion, can improve adhesion between deposit and base metal but it may also cause blistering or peeling of the deposit. This article is concerned only with the influence of heat treatment on the properties of the deposit, with the emphasis on fine gold, gold-cobalt and gold-nickel electrodeposits.

\section{Surface Changes}

Even in fine gold deposits self diffusion causes changes to occur in the surface structure (1). Examination by electron microscopy of fine gold layers which have been heat treated at temperatures higher

Fig, 1 Blisters on the surface of a hard gold deposit containing 0.5 per cent nickel, electroplated on nickel, after being heat treated for 2.5 lours at $800^{\circ} \mathrm{C}$ in air

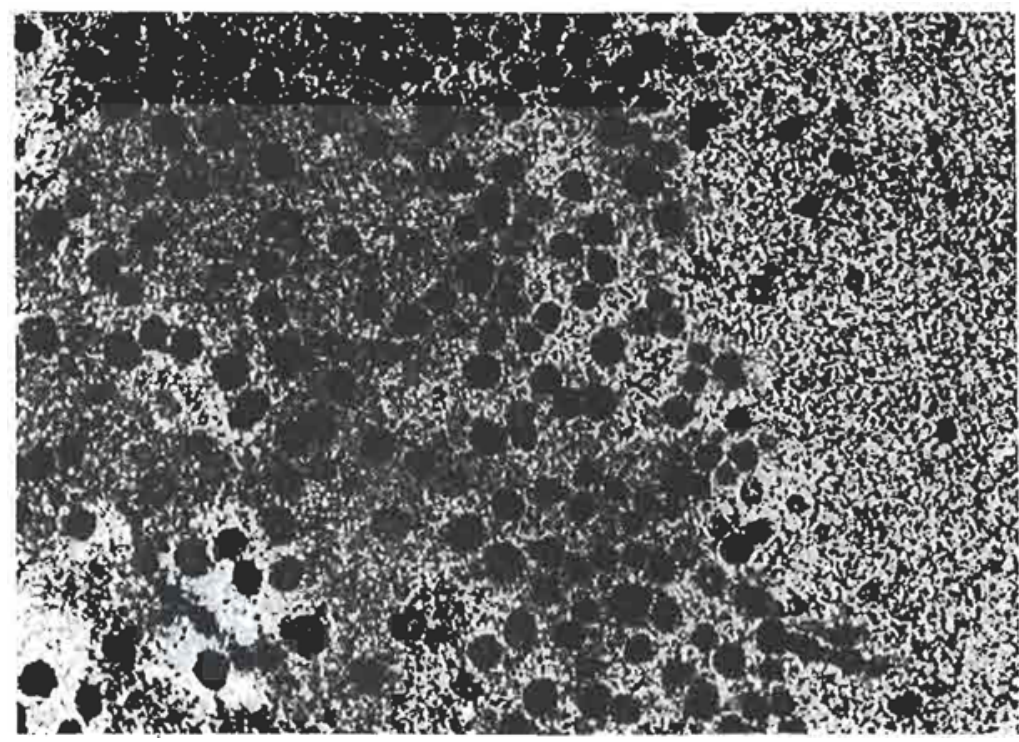


Thickness of Cobalt Oxide and Diffusion Coefficients for Various Times and Temperatures According to (6)

\begin{tabular}{|c|c|c|c|}
\hline $\begin{array}{l}\text { Temperature } \\
{ }^{\circ} \mathrm{C}\end{array}$ & Time, $\mathrm{h}$ & Thickness, $\AA$ & $\begin{array}{l}\text { Diffusion Coefficient, } \\
\qquad \mathrm{cm}^{2} / \mathrm{sec}\end{array}$ \\
\hline 150 & 2927 & 53 & $2.0 \times 10^{-10}$ \\
\hline 150 & 2927 & 58 & $2.28 \times 10^{-16}$ \\
\hline $150^{*}$ & 2927 & 64 & $2.95 \times 10^{-18}$ \\
\hline 100 & 6060 & 7.0 & $1.85 \times 10^{-18}$ \\
\hline 100 & 6060 & 11.0 & $4.2 \times 10^{-18}$ \\
\hline 100 & 6060 & 9.6 & $3.2 \times 10^{-18}$ \\
\hline $100^{*}$ & 7156 & 11.4 & $3.82 \times 10^{-18}$ \\
\hline
\end{tabular}

In addition to surface changes, heat treatment above $400^{\circ} \mathrm{C}$ causes hydrogen gas to be evolved as has been shown by (5). Below $400^{\circ} \mathrm{C}$ the gas evolution is found to be rather low (6).

Microprobe analysis of deposits annealed at $435^{\circ} \mathrm{C}$ in a 3 per cent hydrogen-97 per cent nitrogen atmosphere showed an increase in the concentrations of impurities such as potassium near the blisters (4). This uneven distribution of potassium seems of critical importance for the contact behaviour of heat-treated gold-cobalt alloys commonly used for reed contacts (4).

than $400^{\circ} \mathrm{C}$ reveals a levelling of the sharp peaks and edges of the individual grains, a process which starts at temperatures of about $200^{\circ} \mathrm{C}(1)$.

Depending on temperatures and electroplating conditions hard gold deposits containing cobalt or nickel show more or less pronounced blistering, which is similar whether the samples are annealed in air or in vacuum (Figure 1). This blistering has been investigated extensively $(2,3,4)$ and is very likely due to thermal decomposition of incorporated organic contaminants. This is supported by the fact that brownish-black decomposition products can often be observed on the surface of samples that have been heat treated (4).

Besides the general change in structure which has been referred to above, individual grains tend to grow and sometimes grain boundaries become very pronounced (5). This is due to the diffusion and accumulation of defects at the grain boundaries.
It has recently been established by Augerspectroscopy that, even at temperatures as low as $100^{\circ} \mathrm{C}$, a cobalt oxide layer is formed on hard gold deposits if the layers are annealed in air (6). The table shows the thickness dependence of the cobalt oxide layer on the experimental conditions, as well as the diffusion co-efficients of cobalt in hard gold (6). As would be expected, the amount of oxide film formed on top of the electrodeposit is independent of its thickness. By means of an Arrhenius plot it is possible to obtain the activation energy for diffusion, and this was found to be $28 \pm 6 \mathrm{kcal} / \mathrm{mole}$.

The blistering referred to above is also accompanied by changes within the material. This was checked by experiments in which a 17.5 micron diameter gold wire was electroplated in the usual gold-nickel citrate electrolyte up to a diameter of about $2 \mathrm{~mm}$. In the as-deposited condition it showed a structure similar

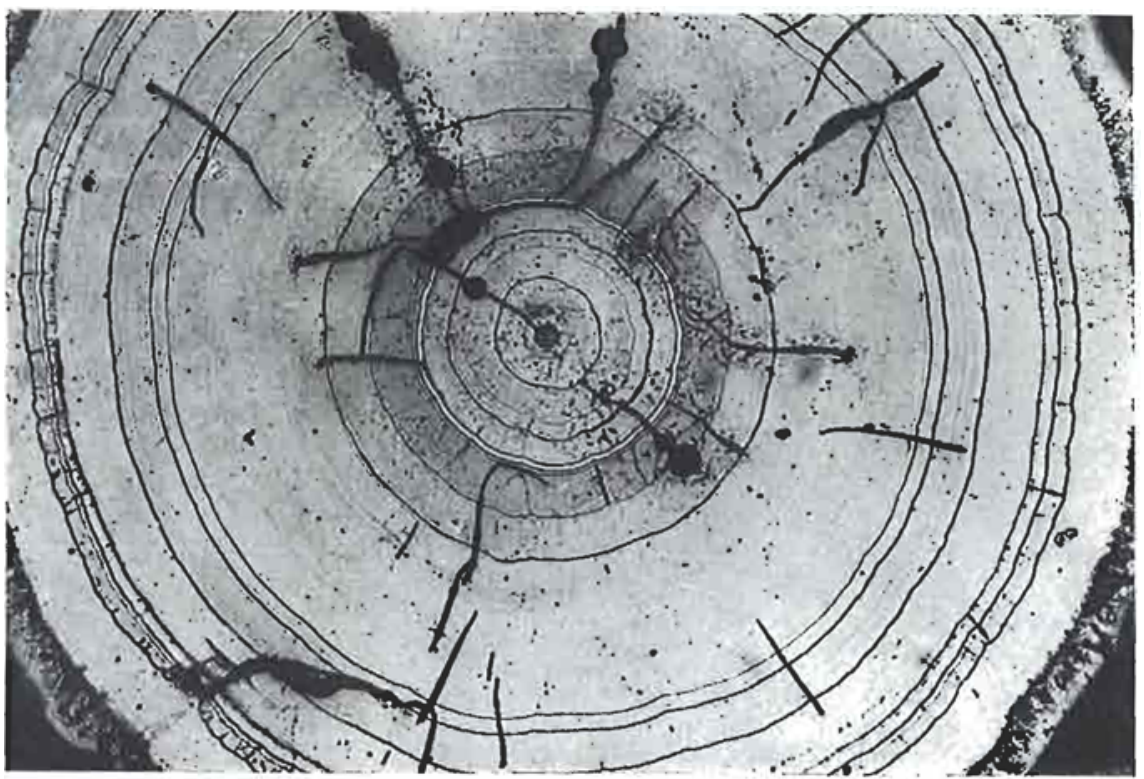

Fig. 2 The structure of a gold wire eleetroplated with gold0.5 per cent nickel showing concentric "tree ring" growth lines and radial stress cracks $\times \mathbf{1 0 0}$ 
Fig. 3 Porous structure of a gold-0.5 pex cent nickel deposit after annealing For 2 hours at $700^{\circ} \mathrm{C}$. Heat treatment at lower temperatures does not produce such pronounced porosity $\quad \times 100$

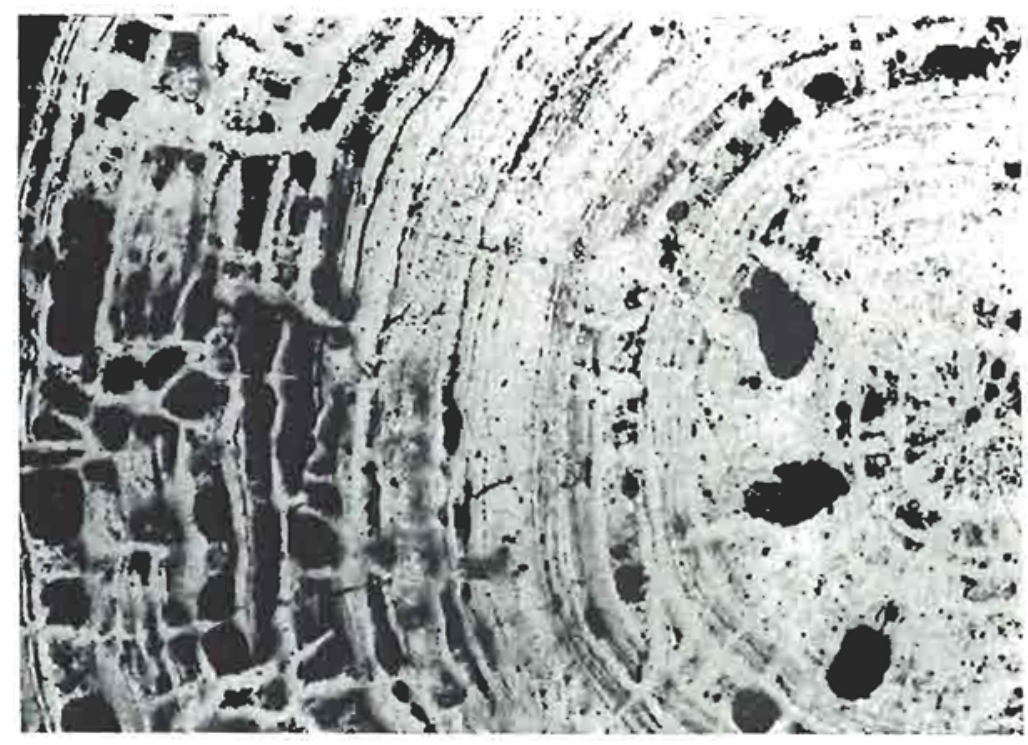

to tree growth rings with a few cracks caused by stress, as shown in Figure 2. The "tree rings" were caused by periodic adjustment of the current density as the deposit thickness increased. The very porous structure which developed after a 2 hour heat treatment at $700^{\circ} \mathrm{C}$ can be seen in Figure 3. The structure is not cracked, but is full of holes. After heat treatment at lower temperatures the cavities are not as pronounced, which might be due to a lower decomposition pressure of the impurities, and the higher strength of the gold matrix.

\section{Tensile Strength and Hardness}

The influence of heat treatment on the tensile strength of fine gold plating, 5 to 250 microns thick, deposited from various electrolytes has been reported recently by several different investigators $(7,8,9,10$, 11). When 350 micron thick deposits electroplated in a sulpnite bath were annealed at $500^{\circ} \mathrm{C}$ a reduction in both yield and tensile strength resulted, but a nearly four-fold increase in elongation was observed. For 5 to 10 microns thick deposits, the tensile strength is similar, but the same heat treatment increases elongation only from about 3 per cent in the as-deposited condition to 8 per cent (10).

Deposits 250 microns thick electroplated from citrate solutions showed a slight reduction in strength $\left(13 \mathrm{~kg} / \mathrm{mm}^{2}\right)$ and in elongation (13 per cent) after being heat treated at $300^{\circ} \mathrm{C}(9)$. In contrast the same procedure increases the elongation of a 25 microns thick deposit from 3.8 to 16 per cent (9), the values for even smaller thicknesses being much lower (5).

Fine gold deposits from phosphate electrolytes exhibit a slight increase in tensile strength after a heat treatment at $100^{\circ} \mathrm{C}$ which is followed by a continuous decrease at higher temperatures, while elongation rises (10). It is interesting that pulse plating increases the elongation by a factor of about two by comparison with normal d.c.-plated deposits, this being independent of annealing temperature (10).
Fig. 4 The relationship between the tengile strength and annealing temperature for a gold. 0.3 per cent cobalt deposit 20 microns thick

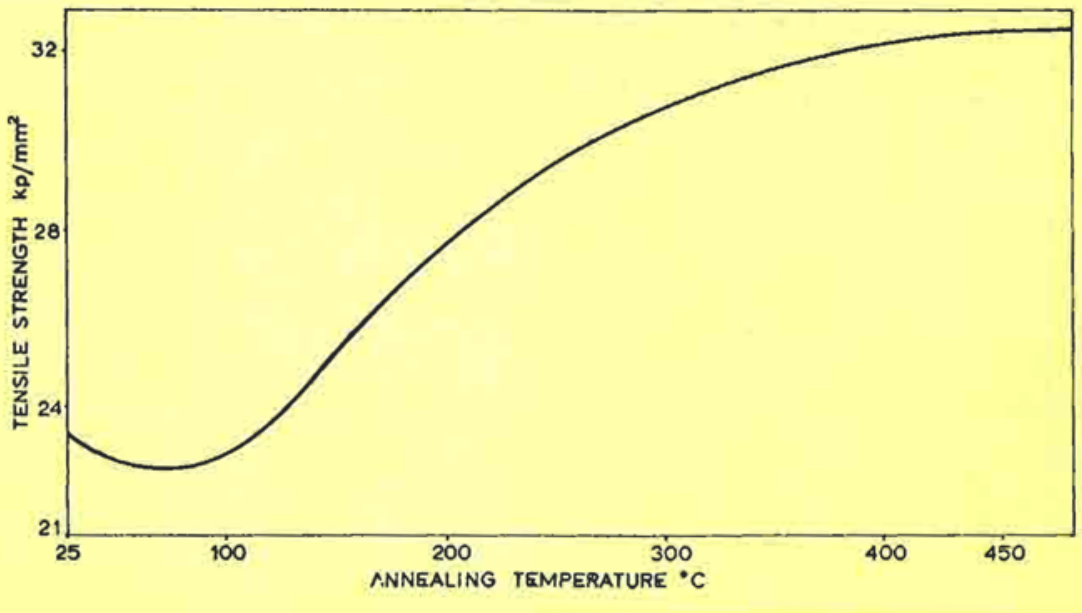




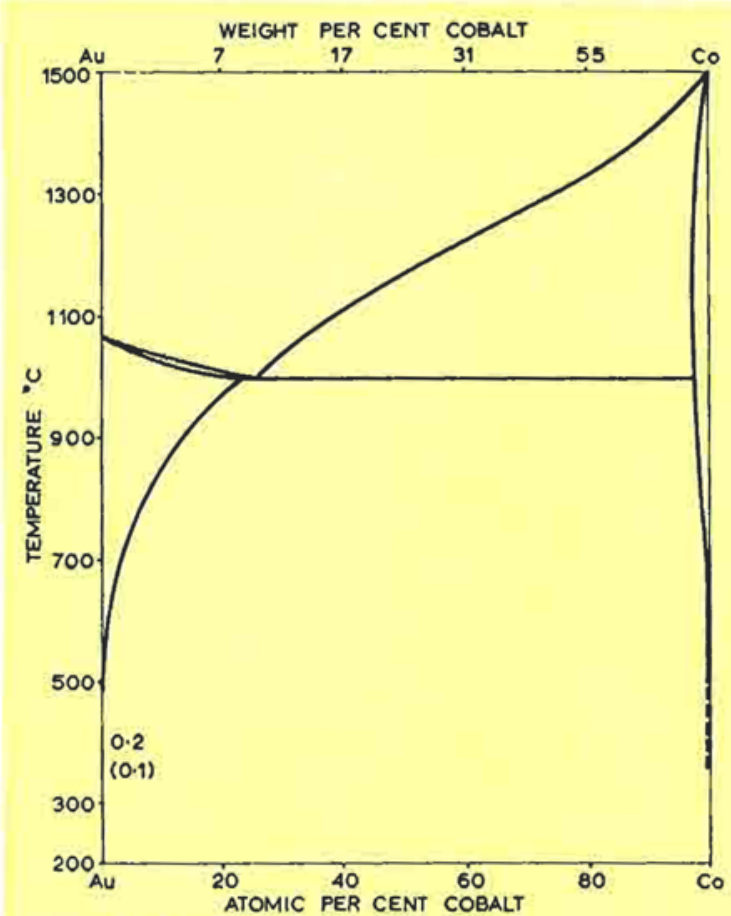

Fig. 5 The gold-cobalt phase diagram according to Hansen (14) shows the equilibrium solubility of cobalt to be considerably lower than 0.5 per cent at room temperature

The influence of a heat treatment on the tensile strength of cobalt-containing hard gold deposits, shown in Figure 4, is also very interesting. The tensile strength vs. annealing temperature curve contains a minimum between 20 and $100^{\circ} \mathrm{C}$. Higher temperatures cause a nearly 50 per cent increase in strength. Even at $700^{\circ} \mathrm{C}$ no decrease in strength could be observed. Elongation does not show any pronounced change.

This effect is caused by precipitation hardening of the deposit. In the as-deposited condition cobalt is present in a supersaturated solid solution. The equilibrium solubility of cobalt is much lower than 0.5 per cent at room temperature (Figure 5 ), and therefore during heating the excessive cobalt starts to segregate, at a rate which increases with temperature, causing the well known effects of dispersion hardening. This effect seems to be so strong that it even overshadows the decrease in tensile strength due to decomposition of the organic constituents.

The solubility of nickel in gold is much higher than that of cobalt, and therefore dispersion hardening cannot occur in hard gold-nickel alloys. As can be seen from Figure 6, the tensile strength in this system drops rather sharply at a critical temperature in a way similar to that of a cold-deformed metal. Elongation shows a steady increase with temperature.

Hardness determinations on hard gold deposits are rather unreliable, especially if the samples have been heat treated, because of the presence of cracks and pores in the material. However, it does seem that heat treatment at $550^{\circ} \mathrm{C}$ reduces the hardness of goldcobalt deposits to about half their as-deposited values.

The influence of a heat treatment on the mechanical properties of 20 microns thick 18 carat gold-coppercobalt alloys has been studied (14). By annealing for 10 minutes at $350^{\circ} \mathrm{C}$ in an inert atmosphere it is possible to obtain high elongations at rather high hardness values.

Heat treatment of gold-copper alloys considerably increases their tensile strength and hardness (13). An alloy with 20 weight per cent copper after being treated for 1 hour at $300^{\circ} \mathrm{C}$ has a tensile strength of about $80 \mathrm{kp} / \mathrm{mm}^{2}$ and a hardness of nearly $500 \mathrm{~kg} / \mathrm{mm}^{2}$ (12). This enhancement is caused by the formation of the ordered AuCu phase within the deposit.

\section{Magnetic Susceptibility and Electrical Conductivity}

As can be expected, the segregation of the cobaltrich phase from gold-cobalt deposits during heat

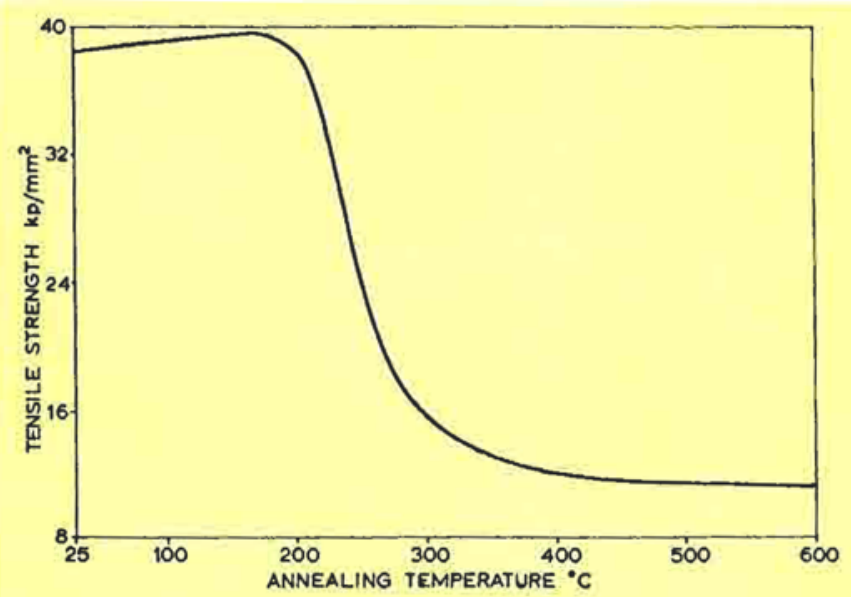

Fig. 6 Tensile strength v8. annealing temperature curve for an electroplated gold- 0.3 per cent nickel deposit $\mathbf{2 0}$ microns thick showing sharp decrease in strength at a critical temperature 
Fig. 7 Relative change in magnetic susceptibility, as a function of temperature, of an electroplated gold- 0.37 per cent cobalt deposit 20 microns thick, during heat treatment. Heating rate $100^{\circ} \mathrm{C}$ per hour

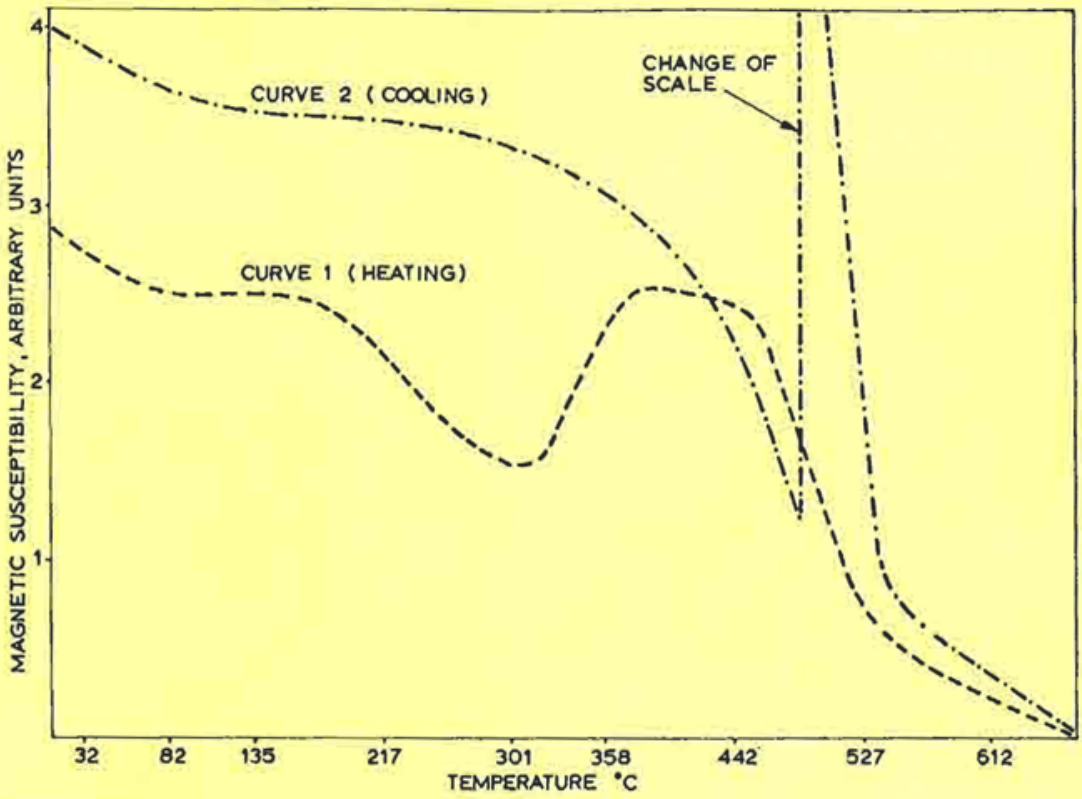

treatment shows up in the behaviour of the susceptibility or resistivity vs. temperature curves.

Electrodeposited gold- 0.37 per cent cobalt alloys in the as-deposited condition are paramagnetic, with a magnetic field independent susceptibility and an extrapolated $\chi$ value at $H \rightarrow \infty$ of $0.256 \mu \mathrm{emu} / \mathrm{g}$. This proves that cobalt is predominantly in solid solution and that the incorporated cobalt compounds are nonmagnetic. The relative change of susceptibility as a function of temperature can be seen in Figure 7, where curves 1 and 2 refer to heated and cooled samples respectively. The heating curves show two maxima at about 200 and $450^{\circ} \mathrm{C}$ (Curve 1). The first maximum may be attributed to decomposition of incorporated cobalt compounds. At $300^{\circ} \mathrm{C}$ a ferromagnetic cobalt-rich cobalt-gold alloy begins to precipitate. At temperatures above $450^{\circ} \mathrm{C}$, the cobalt segregated at lower temperatures dissolves again in the gold matrix and magnetic susceptibility drops.
During cooling of a sample heated above $900^{\circ} \mathrm{C}$ cobalt segregation begins at about $550^{\circ} \mathrm{C}$ and alloys stay ferromagnetic till room temperature (Curve 2).

The position of the maxima depends to a certain extent on the heating and cooling rates of the sample. The corresponding gold-0.3 per cent nickel alloys are diamagnetic, and measurements of magnetic susceptibility up to $600^{\circ} \mathrm{C}$ do not show any kind of magnetic anomaly.

Figure 8 shows the change in the resistivity of deposits containing 0.35 weight per cent cobalt and 0.5 weight per cent nickel during heating between 25 and $700^{\circ} \mathrm{C}$. In this temperature range the gold-nickel layers exhibit a normal linear increase in resistance with temperature. For the gold-cobalt alloys the increase is rather small up to $200^{\circ} \mathrm{C}$, but at temperatures above $200^{\circ} \mathrm{C}$ the curve shows a linear slope which is higher than that obtained for gold-nickel deposits.

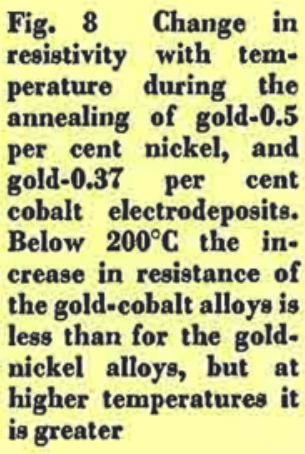

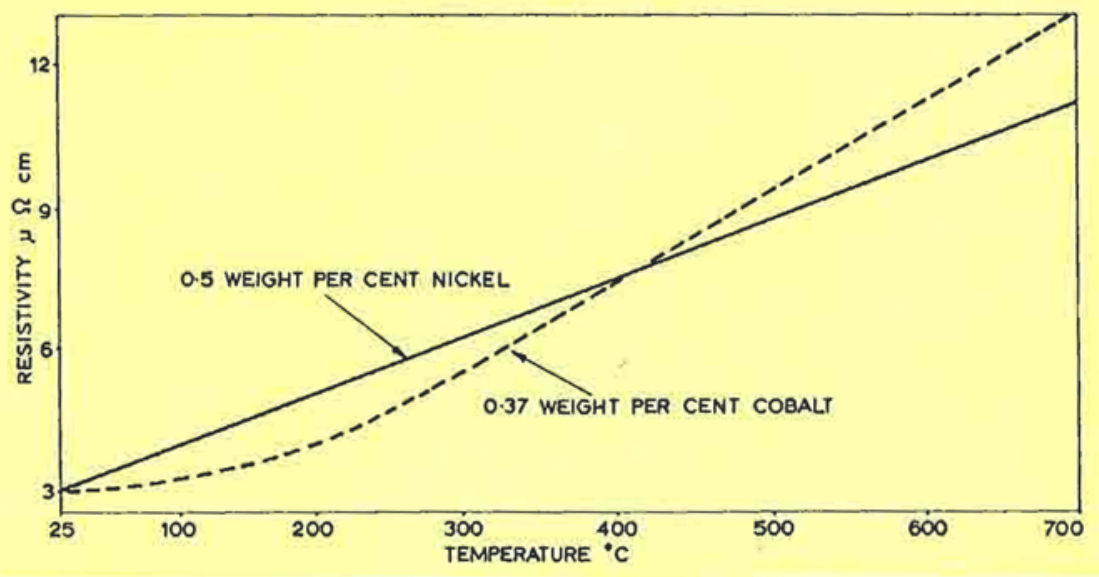


As in the magnetic investigations, one has to keep in mind that the decomposition of incorporated organic material may also have an influence on the resistivity measurements.

\section{Conclusion}

On heating, especially at temperatures higher than $200^{\circ} \mathrm{C}$, nearly all gold deposits show changes in their properties and most of these changes are irreversible. The magnetic behaviour of gold-cobalt alloys is particularly important since electrodeposits which are non-magnetic in the as-deposited condition can become ferro-magnetic following particular heat treatments. This behaviour is not observed in corresponding gold-nickel deposits.

\section{Acknowledgement}

The authors are grateful to the Bayerisches Staatsministerium for support of their investigations via the DFBO (Deutsche Forschungsgesellschaft für Blechverarbeitung und Oberflächenbehandlung).

\section{References}

1 Ch. J. Raub, Gold Bull, 1975, 8, (3), 70

2 M. Antler, "Gold Plating Technology", ed. F. H. Reid and W, Goldie, Electrochemical Publications Ltd., Ayr, Scotland, 1974, p. 483

3 Ch. J. Raub, A. Knödler and J. Lendvay, Plating Surf. Finish., 1976, 63, (1), 35

4 T. A. Davies and P. Watson, Plating, 1973, 60, (11), 1138

5 Ch. J. Raub, J. Lendvay and $\mathrm{H}$. Weiss, unpublished work

6 H. G. Tompkins, f. Electrochem. Soc., 1975, 122, (7), 983

7 J. R. Cady and P. S. Willcox, Plating, 1973, 60, (2), 139

8 F. I. Nobel, D. W. Thomson and J. M. Leibel, Plating, $1973,60,(7), 720$

9 J. W. Dini, Gold Bull., 1973, 6, (4), 99

$10 \mathrm{~J}$. Lendvay and Ch. J. Raub, Metalloberfldche, 1975, 29, (4), 165

11 Ch. J. Raub and J. Lendvay, Galvanotechnik, 1976, 67, (2), 95

12 H. J. Wiesner and W. B. Distler, Plating, 1969, 56, (7), 799

$13 \mathrm{M}$. Hanson, H. R. Khan and Ch. J. Raub, to be published

14 M. Hansen, "Constitution of Binary Alloys", McGrawHili, New York, 1958, 196

\section{Lamellipodia Prefer Gold}

Evidence that single embryonic cells are capable of examining their surroundings and of moving to preferred sites for proliferation has been accumulating. Some kind of exploratory organ appears to be able to detect a favourable area and then to bring about a movement in its direction. An intriguing piece of research sponsored by the National Cancer Institute and carried out by Dr Günter AlbrechtBuehler at the Cold Spring Harbor Laboratory, New York ( $\%$. Cell Biology, 1976, 69, 275-286), has in fact shown that minute fibrous projections which he calls "filipodia", about $2 \mu \mathrm{m}$ in diameter and ranging from 2 to $30 \mu \mathrm{m}$ in length, emerge from the surface of a cell and perform a rapid scanning motion until they attach themselves to the substrate. By using a glass substrate having parts of its surface coated with an evaporated and sintered film of gold, he found that when some of the filipodia made contact with a gold-coated area the cell then extended preferentially towards the gold by means of undulating projections called lamellipodia, most of the cells being found on the gold area after an hour or two.

The mechanism of this preferential movement is as yet unresolved; it is likely, however, that the filipodia react to a certain quality of the substrate and then promote the extension of lamellipodia in the direction in which this quality has been detected.

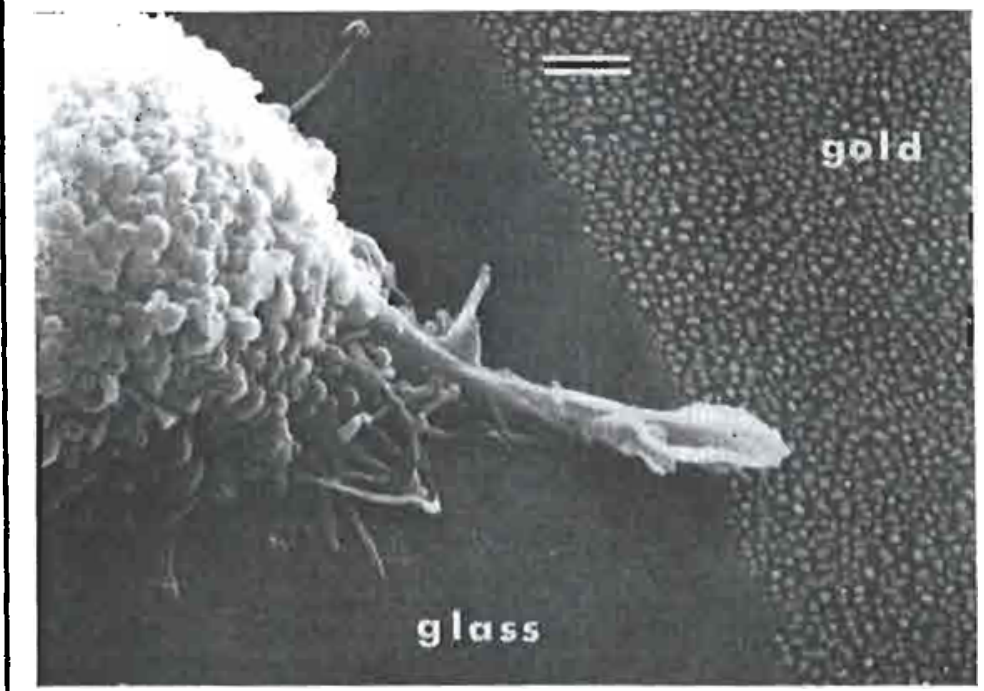

Thisscanning electronmicroscope photograph by Dr Albrecht-Buehler shows a single cell that has settled on a glass surface close to the edge of an evaporated and sintered gold film. Initial contact with the gold by the exploratory flipodia is followed within a few minutes by the projection of a Iamellipodium which reaches out to the gold. After a further hour or two the cell will migrate to the gold area. The bar in the photograph represents $2 \mu \mathrm{m}$ 